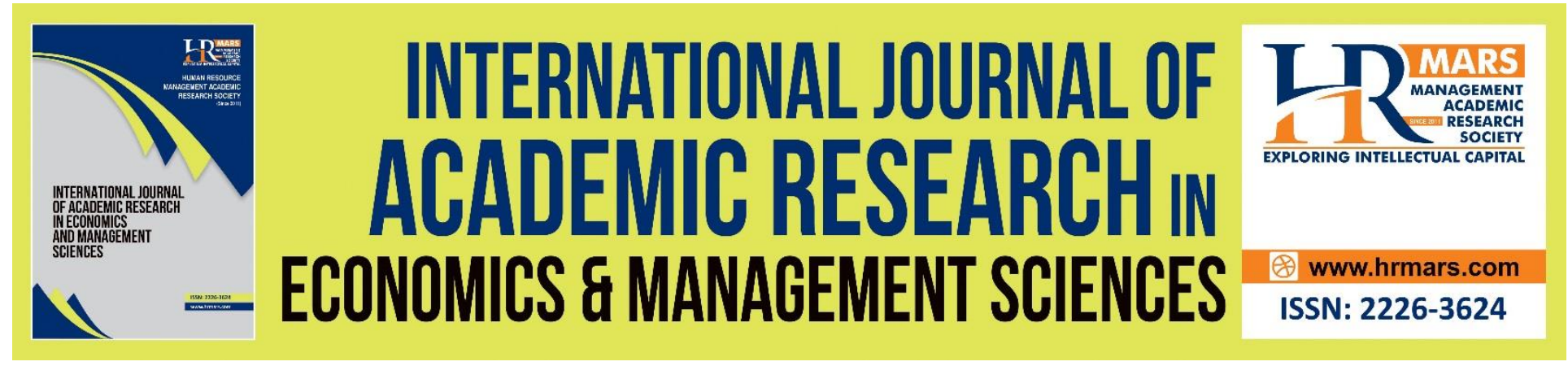

\title{
Artificial Intelligence in Public Sector: A Review for Government Leaders about Al Integration into Government Administrations
}

Hala Ahmed Maalla

To Link this Article: http://dx.doi.org/10.6007/IJAREMS/v10-i4/11911

DOI:10.6007/IJAREMS/v10-i4/11911

Received: 01 October 2021, Revised: 10 November 2021, Accepted: 26 November 2021

Published Online: 13 December 2021

In-Text Citation: (Maalla, 2021)

To Cite this Article: Maalla, H. A. (2021). Artificial Intelligence in Public Sector: A Review for Government Leaders about Al Integration into Government Administrations. International Journal of Acdemic Research in Economics \& Management Sciences, 10(4), 31-45.

Copyright: (C) 2021 The Author(s)

Published by Human Resource Management Academic Research Society (www.hrmars.com)

This article is published under the Creative Commons Attribution (CC BY 4.0) license. Anyone may reproduce, distribute, translate and create derivative works of this article (for both commercial and non-commercial purposes), subject to full attribution to the original publication and authors. The full terms of this license may be seen

at: $\underline{\text { http://creativecommons.org/licences/by/4.0/legalcode }}$

$$
\text { Vol. 10, No. 4, 2021, Pg. } 31 \text { - } 45
$$




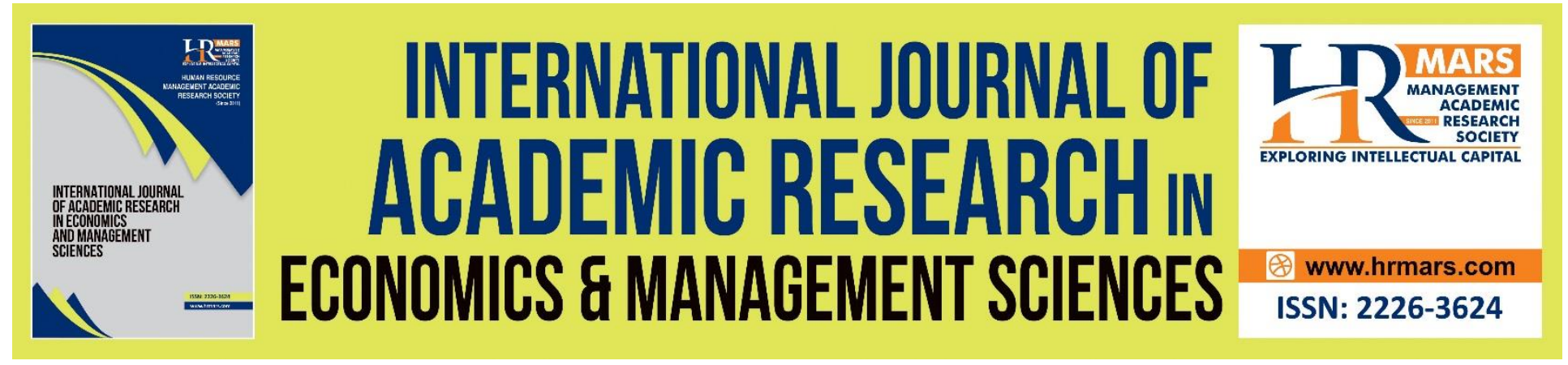

\title{
Artificial Intelligence in Public Sector: A Review for Government Leaders about Al Integration into Government Administrations
}

\author{
Hala Ahmed Maalla \\ Public Administration Department -College of Business Administration- King Saud University \\ Riyadh Saudi Arabia \\ Email: Hala.maallawia@gmail.com
}

\begin{abstract}
In today's public sector, there is an urgent need for efficiency, effectiveness and rapid response to economic and social changes. This change is supported by tremendous technological progress, where artificial intelligence (Al) is one of the most important pillars of digital technology that can dramatically change all sectors of society, including the public sector, its leaders and public servants. It may also help in playing a new role and giving a new legitimacy to the public sector and government work based on modern technology. To the best of our knowledge and due to the lack of a comprehensive vision, a hypothesis that establishes for the possibility of applying artificial intelligence in the public sector. This study aims to shed some light on the need of public sector leaders to Gain a comprehensive and deep understanding of the scope and impact of Albased applications in the public sector as their organizations are fully digitized. Previous studies discussed the application of artificial intelligence, often partially, specialized in the business sector, which generated a research gap that did not address the specificity of the public sector and government work. The methodology of this study is based on collecting, analyzing, and linking relevant ideas from published scientific research to provide an integrated overview of the applications of artificial intelligence in the government sector, taking into account the significant role that this sector plays in the lives of citizens and the rest of the vital sectors.

This study examined the specificity of the application of artificial intelligence in the government sector, the role of governments in ensuring the successful implementation of the artificial intelligence strategy in their departments, and the enormous opportunities and capabilities that artificial intelligence provides to the public sector. The study also focused on the most prominent issues and challenges faced by artificial intelligence in government work, the great role that the partnership between the public and private sectors plays for the success of the application, and how government leaders can play an important role in the development and strengthening of the artificial intelligence community.
\end{abstract}

Keywords: Artificial Intelligence, Public Sector, Government Leaders. 


\section{Introduction}

Governments are currently focusing on creating more efficient, effective and responsive policies and services, and exploring and implementing innovative approaches to public service delivery. At a time of increasing complexity, uncertainty, and change and diversity in the needs of citizens, governments and government leaders need to understand, test and include new ways of doing government work. Today, governments can benefit from Al, and in many countries Al is already being used to design new ways of doing government business. Now, a number of international governments already have strategies to build Al capacity as a national priority. By applying Al technology to government work, we are ushering in a new era of hyper-intelligence that will allow public services and citizens to achieve societal goals. Al may also be used to make existing government operations more effective and accurate. Al can dramatically change the work of government, create new ideas and expectations, increase speed and productivity, and create entirely new approaches to citizen interactions with government. In addition, Al in all its forms can generate powerful new capacities in areas as diverse as national security, public health and safety, education and health care.

\section{Research Justification}

To maximize the benefits of the application of $\mathrm{Al}$ in the public sector, leaders need to consider Al in a strategic and holistic manner. Many government agencies have started planning how to incorporate Al into their missions and technologies. But the decisions they make over the next three years could determine whether they succeed or fail over the next decade, as Al technologies continue to evolve rapidly. This is a very difficult and complicated period to absorb such shifts, which affect all or most of the public sector and its work environment, but the positive side, as mentioned (Grosz et al., 2016) is that most government agencies in countries of the world are now spending a significant amount of time building their cloud capabilities and its big data and digital interoperability, and this effort will help support the next wave of Al technology. The Artificial Intelligence led transformation also promises to open up entirely new horizons in operation and performance, fundamentally changing how government delivers public values to its citizens. In the same vein, implementing Al in the public sector requires a deliberate and strategic path to take advantage of the great opportunities offered by Al, and ultimately create value. Government organizations worldwide have initiated initiatives to implement Al work in the public sector, but the implementation of Al technology is a major challenge for the public sector. According to the findings of the study (Thierer et al., 2017), the bulk of implementing Al solutions "are likely to remain limited and highly specialized." Despite the increase in the use of artificial intelligence in the public sector, the vast majority of research published in refereed scientific journals focuses either on the technical specifications of artificial intelligence, or its uses in the private sector. A recent study by (Sousa et al., 2019) reviewed a recent study of nearly 1,700 scientific papers published on artificial intelligence and found that only 59 of them, or 3.5\%, focused on the use of artificial intelligence in the public sector. As a result, strategic success cannot be achieved simply by introducing artificial intelligence into existing organizations and processes. Maximizing its value requires an integrated suite of fundamental decisions, actions and questions that must be answered, and these responses and decisions will involve complex choices: What requests should be prioritized? Which techniques should be applied? How is the value of AI proven for the workforce? How can IA projects be managed? Should there be internal 
talent, external partners, or both? Consequently, without an overview, individual technological initiatives often go wrong; At best, they do solve easy problems in specialized departments, at worst, they automate already inefficient processes. But to truly transform the organization and unlock new value, successful implementation of Al requires a carefully thought-out strategy from a holistic public sector perspective. The justification of the research is embodied in the need for governmental leaders to form a comprehensive and deep understanding (which includes strategies, opportunities and challenges) of the scope and impact of artificial intelligence in the public sector.

\section{Research Importance}

Given the large role assigned to these leaders when their organizations are digitally transformed, and their adoption of $\mathrm{Al}$ and help them develop successful strategies in its application. In light of these indicators, and given the lack of a comprehensive scientific and practical vision on successfully implementing a comprehensive strategy for artificial intelligence in the government sector so far, this study will shed light on the government work environment, which is governed by many routine and bureaucratic procedures, laws and regulations that represent a major obstacle despite Government agencies possess huge data about citizens distributed in their executive bodies, which represents one of the valuable assets of the government sector. This study will focus on the administrative and organizational aspects of interest to leaders and government employees, and will not delve into the purely technical, technical or economic aspects of artificial intelligence. Another important issue for inter-sectoral Al partnerships are that governments are often disconnected from the world of technology and do not have the skills to integrate advanced solutions. Therefore, for Al to play its role within governments, it is vital that the public sector controls its digital destiny. Citizen-focused governments need enough understanding and experience of how technologies work to provide efficient and effective public services.

\section{Research Questions}

This study aims to answer the following key questions:

1- What role do governments play in the application of artificial intelligence in their various ministries and institutions?

2 - What are the main opportunities and capacities of artificial intelligence in the public sector?

3- What is the role of partnership with the private sector in ensuring the successful application of artificial intelligence in the government sector?

\section{Methodology}

In this study, a general methodology is adopted to see the readiness of public sector leaders to have a comprehensive and deep understanding of the scope and impact of Al-based applications in the public sector as their organizations are fully digitized. Following steps were used to address the methodological approach of this work.

(1) Extensive searching in reputed databases such as WoS and Science direct;

(2) Selecting the most suitable keywords;

(3) Choosing and analyzing the most relevant papers;

(4) Categorizing the papers and organize them in major themes; 
(5) Specify the research gaps to form the further direction of the research.

The collected papers were searched using keywords such as "Al", "Artificial intelligence", "public sector, government leaders in the title, abstracts and keywords fields of the search engine. Due to the credibility of WoS and Scopus, only papers indexed in their databases were carefully analyzed and summarized. The content analysis tool is used due its efficiency when applying the literary survey methodology. We adopted the time frame of 2010-2021. Few of the significant articles, which found in the search, were issued before the timeline, and since they are important and strongly correlated with our study were included.

\section{Integration, Artificial Intelligence into Public Sector}

Digital transformation is fundamentally changing the workplace, particularly in the government sector, demonstrating the importance of artificial intelligence. The McKinsey Global Institute predicts in its 2017 report (Artificial Intelligence is the Digital Maximum Science) that rapid advances in automation and artificial intelligence will have a significant impact on the way we work and our productivity within the next fifteen years." Governments' economic growth rates can be as high as 2 per cent. As a result, Al can create changes and benefits for both the public and private sectors. More specifically, a virtual workforce, called intelligent automation, in addition to increasing labor and capital, where intelligence can Artificial intelligence complements the skills of the existing workforce to cost efficiency and savings In this regard, artificial intelligence can be viewed as a mixture of capital and labor. Artificial intelligence also has a significant economic impact for the government sector, based on an analytical economic study conducted by (Capgemini Consulting) in 2019 specifically analyzing ICT-related GDP growth and Al sales figures, along with the overly optimistic multiplier effect. LG70 (due to increased productivity and efficiency), there is an annual Al impact of $\$ 5.61$ trillion. This causes an additional growth of 1.93 percentage points in global GDP by 2025 , and the study stated that even in the most conservative or neutral scenario (with a size multiplier of 30 or 50), a global impact of $\$ 2.45$ trillion could still be expected. (0.86 point growth) or \$4.03 trillion (1.41 point growth).

Applied studies in the public sector have examined numerous cases to see where the value of Artificial Intelligence lies in government sectors, of all sizes and environments, to get an idea of what government leaders think, about harnessing this technology in the government sector. A report prepared by the Infiniti Research Center for Artificial Intelligence Research during the year 2019 concluded on artificial intelligence projects that governments have tried, implemented or planned across three axes, namely increasing citizen participation, improving operational efficiency, and developing public policy strategies and legislation. The report also highlighted the need for governments to overcome several obstacles to successfully adopt this smart technology, and indicated that government leaders may need to invest in upgrading their legacy IT systems. Failure to do so risks major compatibility problems between technology and human work when the application is integrated into the work. The report also highlights that government officials ensure that their departments have the human, IT and infrastructure resources required for an Al project. Cloud solutions may be sufficient for some Al applications for a while, but the enterprise may need more big data processing and more expensive processing units. In addition, the study (Agarwal, 2018) stressed that government leaders must be ready to hire data scientists and IT experts, who can collaborate to identify complex problems that artificial intelligence can 
solve for a more efficient and effective digital government administration. It seems that one of the common themes between these projects is that many governments participate in exploratory artificial intelligence application projects through collaborative partnerships between the public and private sectors, and with academia and industry, and we will discuss this point in detail later. As (Muller and Bostrom, 2014) indicated in a study that dealt with the opinions of technology experts about the future development of artificial intelligence in the government sector, artificial intelligence is a technology that modern countries cannot abandon, especially after the level of digital development reached by today's societies. Until the vision becomes clear, studies continue to highlight the existence of many complex public policy areas, such as ethical uncertainty, digital data management, privacy, national security, and technical advantage of global technology companies, legal framework, employment, and the acquisition of new skills. They also said that with the release of algorithmic management techniques, the application of the principles of audit, accountability and transparency becomes more important. These complications have made the role of government more important than any other sector. They concluded that it is imperative for countries to achieve the structural, organizational and human transformation required by this new digital era, and to implement the necessary facilities, strategies and regulatory policies to preserve the social well-being of its citizens. Several studies such as (Mikhaylov, 2018; Margetts and Dorobantu, 2019) have confirmed that Al is about making better and more informed decisions, and about automating those decisions, and when it is used in the right way, Al has the ability to make government more efficient and responsive to citizens.

Similarly, just as cyber-security trends have shown how this new digital innovation has created new professions, such as ethical hackers, firewall specialists, data privacy, information security, etc., MIT Sloan Management Review emphasized in a report published in 2017 titled "Jobs that It will be created by artificial intelligence "Artificial intelligence is expected to create new jobs, now government organizations need to develop artificial intelligence programs, supervise and develop artificial intelligence work, based on the course of work and complement artificial intelligence solutions with social skills, etc. In the same context, a recent study conducted by (Capgemini Consulting) in 2019 among nearly 1,000 organizations from the private sector showed that $83 \%$ of companies implementing artificial intelligence created new job roles, while $78 \%$ increased operational efficiency by more than $10 \%$. In addition, the report points out that artificial intelligence does not threaten existing jobs. According to the Global Center for Data Innovation, many employees (physicians, journalists, public servants, police, taxi drivers, etc.)

\section{The Role of Governments in Integration of Al into their Administrations}

Many studies have expected that the use of artificial intelligence will expand in government sectors in various countries around the world, and with the continued development of the applications of these tools and techniques, governments are adopting artificial intelligence, to meet critical and urgent tasks that include, but are not limited to, increasing efficiency, reducing costs, and identifying and neutralizing internal threats. Plans for multiple expenses, answers routine service questions and provides strategic support to national plans. Government departments are also studying additional uses of artificial intelligence in several vital sectors, such as checking compliance with tax laws and regulations, and health and education services, to assess the accessibility of government products and websites. In a study conducted by (Ubaldi et al., 2019) in cooperation with the Organization for Economic Cooperation and Development 
(OECD) They suggested a number of roles that governments could play in relation to Al, and stated that governments could choose one or more of these roles to ensure the success of a successful Al implementation strategy in the public sector. We can understand these roles through: First: The government as a financier or direct investor: Governments can provide funding to support the development and adoption of modern technologies. Second: Government as a smart buyer and co-developer: Governments can act as a smart buyer of existing Al solutions through innovative procurement practices, or as a co-developer through public-private partnerships (PPP) and other forms of collaboration to build new or customized solutions. Third: Government as a regulator or rule-setter: The accelerating innovation cycles of digital technologies require a rethinking and implementation of the types of policies and regulatory tools used. Fourth: Government as regulatory and standard-setter: Governments often have the ability to bring together stakeholders, from many parts of the Al ecosystem (such as citizens, tech experts, companies, organizations, and academics), to help achieve their goals and understand the multiple facets of relevant issues. Fifth: Government as Data Officer: Governments own or keep on behalf of their people, and this is considered a huge amount of data. Sixth: Government as a user and service provider: Governments provide services and tools that have been enabled by or made possible by artificial intelligence techniques, whether for the public or for back office functions (Ubaldi, et al., 2019; OECD, 2019A).

Believing in the growing role of artificial intelligence in the government sector economically and socially, the Organization for Economic Cooperation and Development (OECD) has made several recommendations to the governments of member states on the basics of successful strategies for applying artificial intelligence in government sectors and providing public services. These recommendations were published in a working paper discussed in 2019 entitled "Artificial Intelligence and Its Uses" in the public sector" which are recommendations to governmental leaders and policy makers regarding national policies and international cooperation for trustworthy Al. Although these recommendations go beyond innovation and transformation in the public sector, they seek to help government leaders and public policy makers explore potential avenues for public sector implementation. These recommendations are summarized as Investing in research and development in the field of artificial intelligence which is the basis for the success of any national strategy, fostering a modern digital ecosystem for artificial intelligence, shaping an enabling policy environment for artificial intelligence, Building human capabilities and preparing for labor market transformations, and establishing international cooperation for trustworthy artificial intelligence

\section{Artificial Intelligence Opportunities in the Public Sector}

(Bernd et al., 2019) explained in his analyzes of the government's application of artificial intelligence, that it provides governments with two great opportunities that do not apply to the private sector, which is that it allows them to structure and analyze the huge amount of data they keep about citizens and use it for social benefit. This means that they can identify and reduce inequality of outcomes as well as opportunities. They can also share data with third parties, who can create applications or services that improve citizens' lives, while ensuring that these parties maintain data confidentiality. Al also provides them with a unique opportunity to show how citizens will use and take advantage of these technologies. This is because governments are also 
responsible for setting an example, in the ethical use of $\mathrm{Al}$, regulating how companies apply it and educating citizens to be prepared for its challenges.

The applications of artificial intelligence in the public sector are wide and growing, and exploratory experiments are being conducted all over the world to explore the possibilities of artificial intelligence in government services. In his study (Rahwan, 2018), he achieved positive outcomes in this area. In addition to education, public officials may use artificial intelligence to help them regulate the payment of health and social care payments, detect financial frauds, plan new infrastructure projects, answer citizens' inquiries, and assist in legal consultations, and triage of health care cases in health centers and hospitals, especially in cases of epidemics. It is important to note that the decisions now being made by Al will have a major impact on government jobs and others. The question is, which tasks should machines be entrusted with? And how government executives and public servants should use the time saved by involving $\mathrm{Al}$ in government work.

With the improvement of machine learning capabilities, deep learning and expert systems, and the expansion of making robots more humanlike and possessing many skills, (Shafique, 2018) it is likely that the world's governments will invest more in artificial intelligence research. It is estimated, according to the 2018 US Department of Commerce report, which US government investments in cognitive and synthetic intelligence technology will grow at a compound annual rate of 54.3\% between 2018 and 2021. National and local governments are currently working with academia and industry leaders to implement Al project applications in government service delivery and automate the record backlog government-related. The British government, according to the annual report issued by the Prime Minister's Office for Government Performance for the year 2019, also made significant practical contributions to the development of expert systems, and the trend was based on what others did previously, especially the Americans. Since governments cannot do the integration of Al into the delivery of public services on their own, the UK government's AI industrial strategy has been clear that delivering the grand challenge of Al requires collaboration between universities and the private and public sectors. But although a collaborative approach across sectors is the norm in centers of excellence for applying $\mathrm{Al}$ around the world, the popularity of this strategy includes serious management challenges that impede its success. Therefore, the United Kingdom's perspective on the focus of its $\mathrm{Al}$ investments is based on synergies between government and business.

So (Shafique, 2018) suggest that when artificial intelligence can do the work of public officials in less time, the government may consider reducing the number of its employees, reducing the fees for government services it provides to its citizens or reducing taxes, and it is certain that some governments will follow this option. However, this is not necessarily the preferred option. Governments can instead choose to invest in the quality of their services. It can also repurpose workers' time toward more efficient and effective tasks that require emotional intelligence and creative thinking, all skills at which humans will continue to outperform even the most sophisticated Al software.

Complex government processes, which leave little room for new ideas, turn enthusiastic new public servants into frustrated, as they must strictly adhere to stipulated procedures (and encourage them to leave government work). It is not good for public servants, but it is especially bad for the government itself. Regular surveys of trust in government, carried out by the Organization for Economic Co-operation and Development, show low levels of trust in 
governments in recent years 2018 and 2019 for economic and organizational reasons. So increasing the space for government employees to use their human skills, such as empathy, empathy, creative thinking, and emotional intelligence skills, may help increase citizens' confidence more than indulging in routine work. Humans are much better at this kind of thinking (and feeling) than machines, and it is often the purposeful communication, common sense, and understanding that citizens seek when they interact with their governments. The following figure shows the most important hard and soft skills that are most in demand in jobs, according to the McKinsey Institute for Studies and Consulting report for the year 2020. The following figure represents the conceptual map that should be in the minds of government leaders when implementing any strategy for the application of artificial intelligence in the public sector.

Figure (1) conceptual map for the application of artificial intelligence in the public sector.

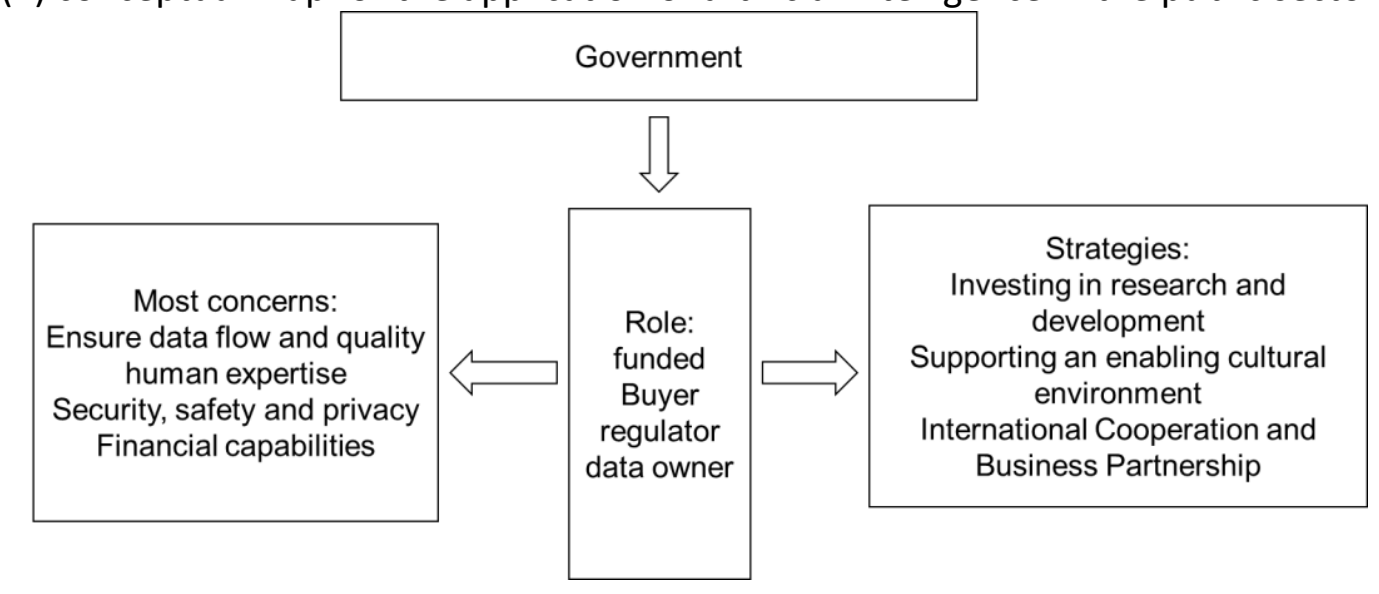

\section{Public-private Partnership to Successfully Al Integrate in Public Sector}

In most countries, public sector businesses are the biggest employers. Given this scope, the application of Al in the public sector may have a significant impact on how our societies develop and how public objectives can be met. Within the scope of research and analysis conducted by (Boyd and Wilson, 2017) in the New Zealand public sector and (Eetgerink, 2019) in the French and British public sector, they found that public organizations and government offices are already experimenting with Al applications but are unable to keep pace with the private sector in this field. But they said that government use cases for Al were a working partnership with the private sector, so relevant expertise could be transferred to government tasks. They noted that there are already pilot programs for the application of artificial intelligence in the public sector that focus on enhancing public service delivery and supporting citizens. The Al application areas listed under the terms "Al process automation," "predictive analytics," "identity analytics," "virtual agents," and "cognitive robots" are of great interest and have significant benefits for the public sector (Manyika et al., 2018). In their study that Al solutions have the potential to solve many productivity problems and enhance overall social developments, but the public sector cannot achieve this vision without full cooperation with private companies that are driving innovative technologies such as Al. Continuous digital development has affected multiple scales of life Modernity (finance, mobility and environment to name a few) thus blurring the lines between sectors, resulting in an integrated and interconnected ecosystem where both opportunities and challenges arise. Neither the private sector nor the public sector alone can manage 
transformation, and a "strategic alliance" between them is needed to make smooth progress towards lasting impact.

Currently, more emphasis is being placed on the automation of public administration and government law. Thus, it is clear that digital transformation is already changing the way government services operate, and represents the relationship between governments and companies, and this point was stressed by (Miller) in his book published in 2018 AD entitled "Preparing for the Future" which supports the previous findings of many Artificial intelligence experts, about the efforts of many governments such as the European Union to establish partnerships with the private sector, to support technological developments, and in this sense, digitization is a good precursor to artificial intelligence. Artificial intelligence differs from digitization in the points that are mainly related to computer science, which are the main pillars of developing Implementation of Al at the government level It is still difficult to say that Al shapes digital governments, but it is clear at the point in which partnership with private companies can improve the ways in which public administration and government services are delivered to their citizens. He added (Miller, 2018) that the most Al-ready governments are those that make significant investments in strong partnership models with private smart technology companies to build Al capabilities. This trend is likely to increase the more software technology companies realize that $\mathrm{Al}$ represents a potential multi-billion dollar opportunity, and the more governments reach out to the private sector to implement cognitive technologies. The PPP has contributed to the emergence of GovTech, which refers to "any technical solution for a public company". This application leverages data to gain valuable insights, leading to enhanced public services and increased collaboration between government and technology companies, as well as increased transparency and accountability in public services.

For example, the European Union Commission adopted the Communication on Artificial Intelligence, which aims to "increase the technological and industrial capacity of the European Union and the polarization of artificial intelligence by the public and private sectors", prepare Europeans for subsequent social and economic changes, and establish the ethical and legal framework for artificial intelligence. France also introduced its Al strategy in 2017 to invest in Al research and talent. China also expects to become the 'global leader in Al innovation' by 2030. Also Denmark and Finland. Many more developed countries announced plans to lead the digital revolution and implement artificial intelligence, considering it an inevitable element of economic competition, development and global leadership. The last of which was the Kingdom of Saudi Arabia, which presented its national strategies for artificial intelligence during the World Summit on Artificial Intelligence held in Riyadh on October 21 and 22, 2020. This strategy is based on six main components: ambition, competencies, policies and regulations, investment, research and innovation, and finally the system, as stated in the national strategy document for data and artificial intelligence issued by the Saudi Authority for Data and Artificial Intelligence (SDAYA). In Japan, the National Institute of Advanced Industrial Science and Technology (AIST) and the Ministry of Economy, Trade and Industry (METI) announced a cooperation aimed at attracting top researchers in artificial intelligence to develop and commercialize Japanese technologies in this field. To this end, the Japan Meteorological Agency, the Japan Patent Office, and the Electricity, Traffic and Transportation authorities are currently implementing Al projects that can help increase the capabilities of human operations in tasks such as patent and trademark 
examination, traffic management and forecasting, and the development of predictive capabilities. For emergency response.

In addition, the Singaporean government recently announced a partnership with Microsoft to develop conversation interfaces for their Smart Nation initiative. The Secretary of State and President of the Smart Nation Initiative also announced the government's plans to explore the use of chatbots in selected utilities. To that end, the Information and Communications Development Authority of Singapore (IDA) is working with Microsoft to integrate conversation information into existing public services as a legitimate proof of concept.

In a series of reports issued by the Organization for Economic Cooperation and Development in the period between 2016 and 2019 regarding the government application of artificial intelligence, the Organization for Economic Cooperation clarified that there is a clear growing competition for the global dominance of artificial intelligence fueled by its comprehensive economic, development and social capabilities. Also, the reports have shown that governments, researching the possibilities of Al now realize that they cannot integrate $\mathrm{Al}$ into the public service without help from the private sector. Whereas cross-sector collaboration is ideal only in theory, as it carries practical challenges that require creating a comprehensive framework that prioritizes $\mathrm{Al}$, for good and creates task-oriented $\mathrm{Al}$ in government and toward efficiency and social improvement rather than just profits and financial returns. The advantages of public-private collaboration in Al are many, as are the legal and practical challenges of implementation. Including conflicts of interest, while governments look to private companies, often multinationals, to develop Al software. So we have two completely different areas, programs and priorities, which can lead to conflict of interest; governments serve the citizens while private companies serve the interests of stakeholders. For example, in terms of the use of citizen data in public services, there are some fundamental issues that come up strongly, who is responsible for protecting citizen data? Who owns it? And who will benefit from the information generated through data analysis? In addition to responsibility, transparency and interpretability: If machine learning makes a mistake against a citizen, who will be held accountable? Government? The machine or company behind the artificial intelligence software? The challenge of defining Al standards for specific sector use is a significant impediment. Therefore, governments need to ensure that a machine can make conscious and legitimate prescriptive choices (OECD, 2019A).

\section{Discussion}

Artificial intelligence is an area of research and application of intelligent technologies that has a significant impact on policy and public services in many respects. In just a few years, it is expected that there will be potential to save approximately a third of public servants' time, allowing them to shift from normal tasks to high-value businesses. Governments can also use Al to shape better policy and decision-making, improve communication and engagement with citizens, and improve the timeliness and quality of public services. While the potential benefits of Al are significant, they are not easy to achieve. The government's use of Al follows that of the private sector; the field of application of artificial intelligence in the public sector is a complex field with many diverse dimensions and real opportunities and challenges.

This study points to the growing importance of artificial intelligence in theory and practice, as well as its leading potential for the public sector at a global level, both positively and negatively. As a result, many countries have realized the high value of Al for public use and have launched 
numerous Al initiatives, benefiting from broad practices from potential application areas. However, for whatever reason, the full range of Al applications has not yet been fully addressed by any government. Related challenges that may impede the successful implementation of $A l$ in the public sector are sometimes overlooked. In the government's periodic reports, it appears that despite significant benefits and recent Al efforts, its implementation in the public sector remains a topic of debate. Since the public sector is a relatively new field of Al application, and many applications have been used as innovative pilot projects, governments and public authorities may not be aware of the topic as a whole, both of the opportunities for Al applications and related challenges. This is exacerbated by the fact that public sector Al research is still in its infancy and so far fails to provide an integrated view of public sector Artificial Intelligence applications and challenges. In response to this shortcoming, this study sought to develop a comprehensive understanding of $\mathrm{Al}$, provide an overview of its applications and challenges in the public sector, summarize all findings and insights from research related to Al in the government sector, and specific guidelines for government leaders dealing with applying of $\mathrm{Al}$ in their organizations.

To ensure the successful application of Al, public organizations can initiate educational programmes, such as training courses or workshops for their employees to develop and enhance skills specific to Al, which may also facilitate changes and reduce potential negative impacts in the context of workforce replacement and transition. These employee education measures also hold promise. Also, on issues of IT or data security and privacy in the context of Al, to ensure that we take charge of these critical areas that have the greatest impact on and are most relevant to citizens. Sensitive aspects of concern among citizens, such as workforce replacement or Al safety and privacy, can generally be addressed through actions that create transparency, regarding the potential consequences of Al-based changes in the work, social and personal environment in the form of information updating and ownership. This can allay potential fears among employees or citizens and bring about social acceptance and trust in Al. To this end, Al applications should be implemented progressively in the form of smaller, ethically harmless pilot projects that can be well managed and easily understood by all actors involved, promising rapid success and encouraging social acceptance of Al. In terms of effectiveness and efficiency, it is logical that government leaders should first address these easy-to-solve problems. On the other hand, governance and ethical challenges can be difficult to address and are a long-term issue. But it is imperative that public organizations establish Al governance with capacities, structures and processes that regulate issues of accountability, accountability, privacy, security, etc.

\section{Conclusion}

Through this review, we have reached some important conclusions; firstly, despite the increasing investments in Al research and the growing number of research contributions, Al for general use remains a recent area of research that falls short of describing the applications and challenges associated with it. Consequently, this gap also arises from the lack of a common definition and understanding of $\mathrm{Al}$ in a variety of academic fields. Therefore, it is important to first clarify the importance of Al, prior to identifying and describing the areas of application of Al and related challenges in the public sector.

Secondly, ensure that $\mathrm{Al}$ is used responsibly in all areas of government. In addition, there should be strong communication between policy makers, Al engineers and scientists. Government officials and those responsible for designing, programming and implementing artificial 
intelligence systems must share responsibility for implementing and supporting the government's strategic standards. Experts in public policy, public administration, governance, and administrative law should have regular, open conversations with engineers and technologists, so that these groups are well aware of the potential misuse of Al. In this way, they can develop correct and quick responses and avoid many technical and security issues.

Future research will examine the challenges of government and national differences. Since research on Al and the public sector is still at an early stage, there are many research opportunities available that scientists need to address, in order to expand our theoretical and empirical knowledge in this field. The study seeks to provide early conceptual input by providing an integrated analysis of Al applications and challenges in the public sector.

\section{Study Contribution}

The main contribution of this paper is meant to providing a comprehensive understanding of Al implementation strategies for government leaders who may have not sufficient technical background to understand Al technologies, despite the decisions that should be taken by government leaders which determines success or failure of implemented strategy. Moreover, the study is distinguished by the fact that it collects all the scientific results that government leaders need to understand about all the organizational and social dimensions of artificial intelligence in their organizations. So far, field evidences confirms that any government has not yet fully addressed the challenges of applying artificial intelligence in the government sector. Although the massive advantages provided by Al technologies, still the public sector considered as a relatively new field of Al's applications. Published scientific studies have shown a little work done

in the application of artificial intelligence in the government sector compared to the high focus on the business sector, which put the government sector in great strides. To conclude, government leaders have many responsibilities and challenges, and we hope this study will guide them in successfully implementing government Al strategies.

\section{Reference}

Agar, N. (2019). How to Be Human in the Digital Economy. In How to Be Human in the Digital Economy. https://doi.org/10.7551/mitpress/11933.001.0001

Agarwal, P. K. (2018). Public Administration Challenges in the World of Al and Bots. Public Administration Review, 78(6), 917-921. https://doi.org/10.1111/puar.12979

Betaller, C., \& Harris, J. (2016). Turning Artificial Intelligence into Business Value. Today. Accenture, 1-16.

Boyd, M., \& Wilson, N. (2017). Rapid developments in Artificial Intelligence: how might the New Zealand government respond? Policy Quarterly, 13(4).

https://doi.org/10.26686/pq.v13i4.4619

Bughin, J., Manyika, J., Woetzel, J., Mattern, F. M., Chui, S., Lund, A., Madgavkar, S., Ramaswamy, J., Cadena, A., Dobbs, R., George, K., Gupta, R., Hazan, E., Labaye, E., Leke, A., \& Nyquist, S. (2017). A Future That Works: Automation, Employment, and Productivity. McKinsey Global Institute, January.

Capgemini. (2017). Unleashing the potential of Artificial Intelligence in the Public Sector. Capgemini, 1-10. https://www.capgemini.com/consulting/wpcontent/uploads/sites/30/2017/10/ai-in-public-sector.pdf 
Eetgerink, K. (2019). the Government is coming from artificial intelligence, A comparative case study of France and the United Kingdom. Leiden university.

Hawksworth, J., Kupelian, B., Berriman, R., \& Mckellar, D. (2017). UK economic outlook.

Johnson, D. G. (2015). Technology with No Human Responsibility?, International Journal of Business Ethics (Vol. 127, Issue 4). https://doi.org/10.1007/s10551-014-2180-1

Legg, S., \& Hutter M. (2007). A collection of definitions of intelligence. Frontiers in Artificial Intelligence and Applications, 157, 17-24.

Lever, R. (2017). Tech world debate on robots and jobs heats up.

Malik, A., Srikanth, N. R., \& Budhwar, P. (2020). Digitisation, Al and HRM. In J. Crashaw \& P. Budhwar (Eds.) Strategic Human Resource Management.

Margetts, H., Dorobantu, C. (2019). Rethink government with Al. In Nature (Vol. 568, Issue 7751). https://doi.org/10.1038/d41586-019-01099-5

Mehr, H. (2017). Artificial Intelligence for Citizen Services and Government. Harvard Ash Center Technology \& Democracy, August.

Mikhaylov, S. J., Esteve, M., \& Campion, A. (2018). Artificial intelligence for the public sector: Opportunities and challenges of cross-sector collaboration. Philosophical Transactions of the Royal Society A: Mathematical, Physical and Engineering Sciences, 376(2128). https://doi.org/10.1098/rsta.2017.0357

Miller, R. (2018). Transforming the future (open access): Anticipation in the 21st century. In Transforming the Future (Open Access): Anticipation in the 21st Century. https://doi.org/10.4324/9781351048002

Müller, V. C., \& Bostrom, N. (2016). Future Progress in Artificial Intelligence: A Survey of Expert Opinion. https://doi.org/10.1007/978-3-319-26485-1_33

Newman, D. (2017). Artificial intelligence: To be feared or embraced. Forbes.

OECD. (2019). State of the art in the use of emerging technologies in the public sector. In OECD Working Papers on Public Governance (Issue 31).

Rahwan, I. (2018). Society-in-the-loop: programming the algorithmic social contract. Ethics and Information Technology, 20(1). https://doi.org/10.1007/s10676-017-9430-8

Schneider, T. (2019). Your agency isn't ready for Al.

Shafique, A. (2018). Forget jobs. Will robots destroy our public services.

The IEEE Global Initiative. (2017). Ethically Aligned Design: A Vision for Prioritizing Human Wellbeing with Autonomous and Intelligent Systems, Version 2. In leee.

Thierer, A., Castillo O'Sullivan, A., \& Russell, R. (2017). Artificial intelligence and public policy. Mercatus research. Mercatus Center at George Mason University.

Van Ooijen, C. B. U. B. W. (2019). A data-driven public sector: Enabling the strategic use of data for productive, inclusive and trustworthy governance.

Whittaker, M., Crawford, K., Dobbe, R., Fried, G., Kaziunas, E., Mathur, V., West, M. S., Richardson, R., Schultz, J., \& Schwartz, O. (2018). Al Now Report 2018. In Al Now (Issue December).

Wilson, H. J., Daugherty, P. R., \& Morini-Bianzino, N. (2017). The jobs that artificial intelligence will create. MIT Sloan Management Review, 58(4).

https://doi.org/10.7551/mitpress/11645.003.0020

Wirtz, B. W., Weyerer, J. C., \& Geyer, C. (2019). Artificial Intelligence and the Public SectorApplications and Challenges. International Journal of Public Administration, 42(7), 596-615. 
INTERNATIONAL JOURNAL OF ACADEMIC RESEARCH ECONOMICS AND MANAGEMENT SCIENCES Vol. 10, No. 4, 2020, E-ISSN: 2226-3624 @ 2020 HRMARS

https://doi.org/10.1080/01900692.2018.1498103 